\title{
Tooth wear in captive rhinoceroses (Diceros, Rhinoceros, Ceratotherium: Perissodactyla) differs from that of free-ranging conspecifics
}

Lucy A. Taylor ${ }^{1,2}$, Dennis W.H. Müller ${ }^{3,4}$, Christoph Schwitzer ${ }^{1}$, Thomas M. Kaiser ${ }^{5}$, Daryl Codron ${ }^{3,6}$, Ellen Schulz $^{5}$, Marcus Clauss ${ }^{3,7}$

${ }^{1}$ Bristol Zoological Society, clo Bristol Zoo Gardens, Clifton, Bristol BS8 3HA, UK

${ }^{2}$ School of Biological Sciences, University of Bristol, Woodland Road, Bristol BS8 1UG, UK

${ }^{3}$ Clinic for Zoo Animals, Exotic Pets and Wildlife, Vetsuisse Faculty, University of Zurich, Winterthurerstr. 260, 8057 Zurich, Switzerland

${ }^{4}$ National Park 'Bavarian Forest', Freyunger Str. 2, 94481 Grafenau, Germany

${ }^{5}$ Biocenter Grindel and Zoological Museum, University of Hamburg, Martin-Luther-King-Platz 3, 20146 Hamburg, Germany

${ }^{6}$ Florisbad Quaternary Research Department, National Museum, Po Box 266, Bloemfontein, 9301, South Africa

${ }^{7}$ E-mail:mclauss@vetclinics.uzh.ch

Key words: Rhinoceros, mesowear, tooth wear, captivity, nutrition, browser, grazer

\begin{abstract}
Tooth wear can affect body condition, reproductive success and life expectancy. Poor dental health is frequently reported in the zoo literature, and abrasion-dominated tooth wear, which is typical for grazers, has been reported in captive browsing ruminants. The aim of this study was to test if a similar effect is evident in captive rhinoceros species. Dental casts of maxillary cheek teeth of museum specimens of captive black (Diceros bicornis; browser), greater one-horned (Rhinoceros unicornis; intermediate feeder) and white rhinoceroses (Ceratotherium simum; grazer) were analysed using the recently developed extended mesowear method for rhinoceroses. Captive D. bicornis exhibited significantly more abrasion-dominated tooth wear than their free-ranging conspecifics $(p<0.001)$, whereas captive $C$. simum exhibited significantly less abrasion-dominated tooth wear, particularly in the posterior cusp of the second molar ( $p=0.005)$. In $R$. unicornis, fewer differences were exhibited between free-ranging and captive animals, but tooth wear was highly variable in this species. In both free-ranging and captive D. bicornis, anterior cusps were significantly more abrasiondominated than posterior cusps $(p<0.05)$, which indicates morphological differences between cusps that may represent functional adaptations. By contrast, tooth wear gradients between free-ranging and captive animals differed, which indicates ingesta-specific influences responsible for inter-tooth wear differences. Captive D. bicornis exhibited more homogenous tooth wear than their free-ranging conspecifics, which may be caused by an increase in the absolute dietary abrasiveness and a decrease in relative environmental abrasiveness compared to their freeranging conspecifics. The opposite occurred in $C$. simum. The results of this study suggest that diets fed to captive browsers are too abrasive, which could result in the premature loss of tooth functionality, leading to reduced food acquisition and processing ability and, consequently, malnourishment.
\end{abstract}

\section{Contents}

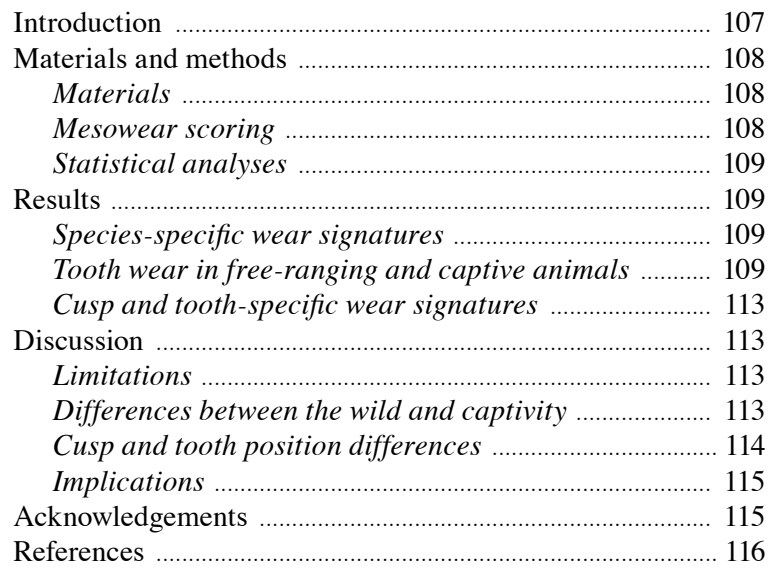

\section{Introduction}

Tooth wear experienced by free-ranging ungulates corresponds to feeding type. Browsers have attritiondominated tooth wear, characterised by an occlusal relief (OR) that is high and a cusp shape (CS) that is sharp, whereas grazers have abrasion-dominated tooth wear, characterised by low OR and blunt CS (Fortelius and Solounias, 2000). To retain tooth functionality on high abrasion diets, grazers have evolved high-crowned (hypsodont) teeth, which are vertically elongated, enabling the tooth to wear for longer (Janis, 1988). Thus, 
browsers, which generally have low-crowned teeth, may not be adapted to high abrasion diets (Damuth and Janis, 2011). Excessive tooth wear has been found to influence body condition, reproductive success and longevity in many species (Skogland, 1988; Ozaki et al., 2010), which is attributed to reduced food acquisition and processing ability, leading to negative energy balance (Kojola et $a l .$, 1998). In captive wildlife, poor dental health is frequently reported (Martin Jurado et al., 2008), and abrasion-dominated tooth wear has been documented in captive browsing ruminants, such as giraffe (Giraffa camelopardalis Linnaeus, 1758) (Clauss et al., 2007). Captive browsing ruminants have a significantly shorter relative life expectancy than mixed feeders and grazers, which suggests there are problems providing appropriate food in captivity (Müller et al., 2011). Conversely, grazing ruminants, such as American bison (Bison bison Linnaeus, 1758), experience less abrasiondominated tooth wear in captivity, and age at a slower rate (Kaiser et al., 2009; Lemaître et al., 2013). Therefore, unnatural tooth wear could be affecting captive animal health, welfare and longevity and, consequently, conservation strategies for captive ungulates.

The Rhinocerotidae, comprising all five extant rhinoceros species, are one of the most threatened families of mammals on Earth. Two monotypic genera and three species of rhinoceros are classified as Critically Endangered on the IUCN Red List, one as Vulnerable and one as Near Threatened. In addition to in situ conservation efforts in increasingly small and isolated habitat fragments, conservation breeding programmes in zoos, which exist for three of the five rhinoceros species, are a vital tool for ensuring their survival. Yet, differences in tooth wear between free-ranging and captive rhinoceroses have not been quantified, and their potential impact on the longevity, and hence lifetime reproductive output, is unknown.

Analyses of tooth wear, using the mesowear method, have been used extensively in dietary and habitat reconstruction (Fortelius and Solounias, 2000) and to compare the tooth wear patterns experienced by free-ranging and captive ruminants (Clauss et al., 2007; Kaiser et al., 2009). Recently, an extended mesowear method was developed by Winkler and Kaiser (2011) and adapted for rhinoceroses, facilitating the detection of inter-cusp and inter-tooth wear pattern differences (Taylor et al., 2013). In free-ranging black rhinoceros (Diceros bicornis Linnaeus, 1758; browser), the anterior cusps were consistently more abrasion-dominated than the posterior cusps, which may reflect a morphological adaptation to browse. In addition, both $D$. bicornis and the greater one-horned rhinoceros (Rhinoceros unicornis Linnaeus, 1758; mixedfeeder) had a significant tooth wear gradient, with teeth becoming less abrasion-dominated along the tooth row. Taylor et al. (2013) suggested that tooth wear gradients may develop due to relative changes in abrasiveness of the ingesta within the oral cavity; in particular, environmental (external) abrasives may affect the anterior teeth more severely before bolus formation. By contrast, high absolute amounts of ingested abrasives may override other signals, leading to homogenous tooth wear in white rhinoceros (Ceratotherium simum Gray, 1868; grazer). Comparing the tooth wear experienced by free-ranging and captive rhinoceroses could differentiate factors caused by morphology and ingesta-specific influences, because morphological constraints will remain consistent between the wild and captivity whereas ingestaspecific influences may vary in a systematic way. Therefore, the aim of this study was to quantify the degree of tooth wear observed in free-ranging and captive D. bicornis, $R$. unicornis and C. simum in order to establish whether different wear patterns are experienced in captivity.

\section{Material and methods}

\section{Materials}

We investigated 49 museum specimens of Diceros bicornis, Rhinoceros unicornis and Ceratotherium simum from 19 zoological museums and collections (Online Appendix S1). C. simum was treated as one species, instead of dividing it into $C$. simum and $C$. cottoni as recently suggested (Groves et al., 2010) due to the small sample size for this genus. Measurements on living specimens were not possible due to the invasiveness of the method. Only specimens with known origin from captivity were selected. Dental casts were produced of either the left or the right maxillary (upper) tooth row. A negative mould was made with Provil novo Light C.D. 2 fast set EN ISO 4823, type 3, light and Provil novo Putty regular set EN 24823 (Heraeus Kulzer GmbH, Hanau, Germany) polysiloxane dental moulding putty. One-to-one positive casts were produced by filling the moulds with epoxy resin Injektionsharz EP (ReckliChemiewerkstoff, Herne, Germany).

\section{Mesowear scoring}

The permanent second, third and fourth premolar (P2, P3 and P4) and the first and second molar (M1 and M2) were analysed using the adjusted rhinoceros mesowear 
method (Taylor et al., 2013). Occlusal relief (OR) and cusp shape (CS) were scored separately for the anterior and posterior cusp position due to the asymmetry of rhinoceros teeth. Rhinoceros-adjusted OR categories of 'high-high' (height/length $\geq 0.125)$, 'high' $(<0.125$ $0.083)$, 'high-low' ( $<0.083-0.0417)$, 'low' $(<0.0417>0.00)$ and 'flat-negative' $(\leq 0)$, were used. CS were scored as 'sharp', 'round-sharp', 'round', 'round-round' or 'blunt' according to the degree of facet development. In addition, the posterior M2 was scored using the 'classical' mesowear method of Fortelius and Solounias (2000), with rhinoceros adjusted OR, for comparisons with previous studies (with OR scored as 'high' $(\geq 0.03)$ or 'low' $(<0.03)$ and CS as 'sharp', 'round' or 'blunt'). Digital callipers and a triplet hand lens (10x-18mm) were used, when required, to differentiate OR and CS.

As ontogeny can affect mesowear (Rivals et al., 2007), and specimen ages were unknown, the wear stage chart of Taylor et al. (2013) was used to ensure all specimens were in the same dental functional stage, excluding young and old specimens. Wear stage 6 was considered for $D$. bicornis and stages 6-7 for $R$. unicornis and $C$. simum. All pathological teeth were excluded.

Both mesowear methods were converted into a mesowear score for analysis. The extended mesowear OR and CS were converted into scores from 0 'high-high'/ 'sharp' up to 4 'flat-negative'/ 'blunt'. A mean of OR and CS was then calculated as the mesowear score (Taylor et al., 2013). 'Classical' mesowear results were converted into a combination score of 0 'high' and 'sharp', 1 'high' and 'round', 2 'low' and 'round', 3 'low' and 'sharp' and 4 'low' and 'blunt' (Kaiser et al., 2009).

\section{Statistical analyses}

Data from this study were compared to data on freeranging specimens from Taylor et al. (2013). Species differences within each group (free-ranging or captive) were tested using Kruskal-Wallis tests on the posterior M2 for OR, CS and mesowear score.

Overall differences between free-ranging and captive specimens in each species were tested using linear mixed-effects (LME) models with fixed effects of Origin * Tooth position (Cusp position) and random effect of Individual specimen for the premolars (P2-P4) and molars (M1-M2) separately due to tooth wear gradients. Due to broken cusp and wear stage exclusions, sample sizes were unequal. Balanced subsamples were taken separately for the anterior and posterior cusp within each tooth to minimise loss of data. Totally balanced subsamples were tested, but resulted in substan- tial data loss ( $R$. unicornis $\mathrm{n}=5)$ without changing the results. Random subsamples were taken using the statistical program $\mathrm{R}$ version 2.15.2 (R Core Team, 2012). We used restricted maximum likelihood (REML) and calculated denominator degrees of freedom using Sattherthwaite's approximation. Differences between freeranging and captive specimens for each individual cusp were tested on the full dataset using Welch's two sample $t$-tests, which does not assume equal variances and sample sizes (Ruxton, 2006).

Intra-species differences along the tooth row were tested using LME models with fixed effects of Cusp position and Tooth position (nested in Cusp position) and random effect of Individual specimen for the CS, OR and mesowear score for each species and origin using the subsample data. Tooth position differences were subsequently tested separately in the anterior and posterior cusp tooth row using one-way analyses of variance (ANOVA) and Dunnett's T3 post hoc test.

Statistical analyses were conducted in IBM $^{\circledR}$ SPSS $^{\circledR}$ Statistics 19 software (SPSS Inc., Chicago, IL) and R version 2.15.2 (R Core Team, 2012). The significance level was set to $p<0.05$.

\section{Results}

\section{Species-specific wear signatures}

Occlusal relief (OR) and mesowear scores in the posterior M2 differed significantly between the three species within both the free-ranging (Kruskal-Wallis: $p<0.001$ ) and captive animals $(p<0.01)$. However, in contrast to the free-ranging animals, no significant difference was detected in cusp shape (CS) between captive $D$. bicornis, $R$. unicornis and C. simum in the posterior M2 (freeranging: $p<0.001$; captive: $p=0.140$ ).

\section{Tooth wear in free-ranging and captive animals}

Overall, the CS, OR and mesowear scores in both premolars and molars were significantly more abrasiondominated in captive $D$. bicornis (LME: all $p<0.001$ ), and significantly less-abrasion dominated in captive $C$. simum (all $p<0.05$ ), compared to their respective freeranging conspecifics (Table 1). In $R$. unicornis, no differences were detected in molar CS ( $p=0.134)$, but overall mesowear scores of captive $R$. unicornis were more abrasion-dominated than their free-ranging conspecifics (all $p<0.05$ ). There was a subjective impression that captive specimens of all species had more 

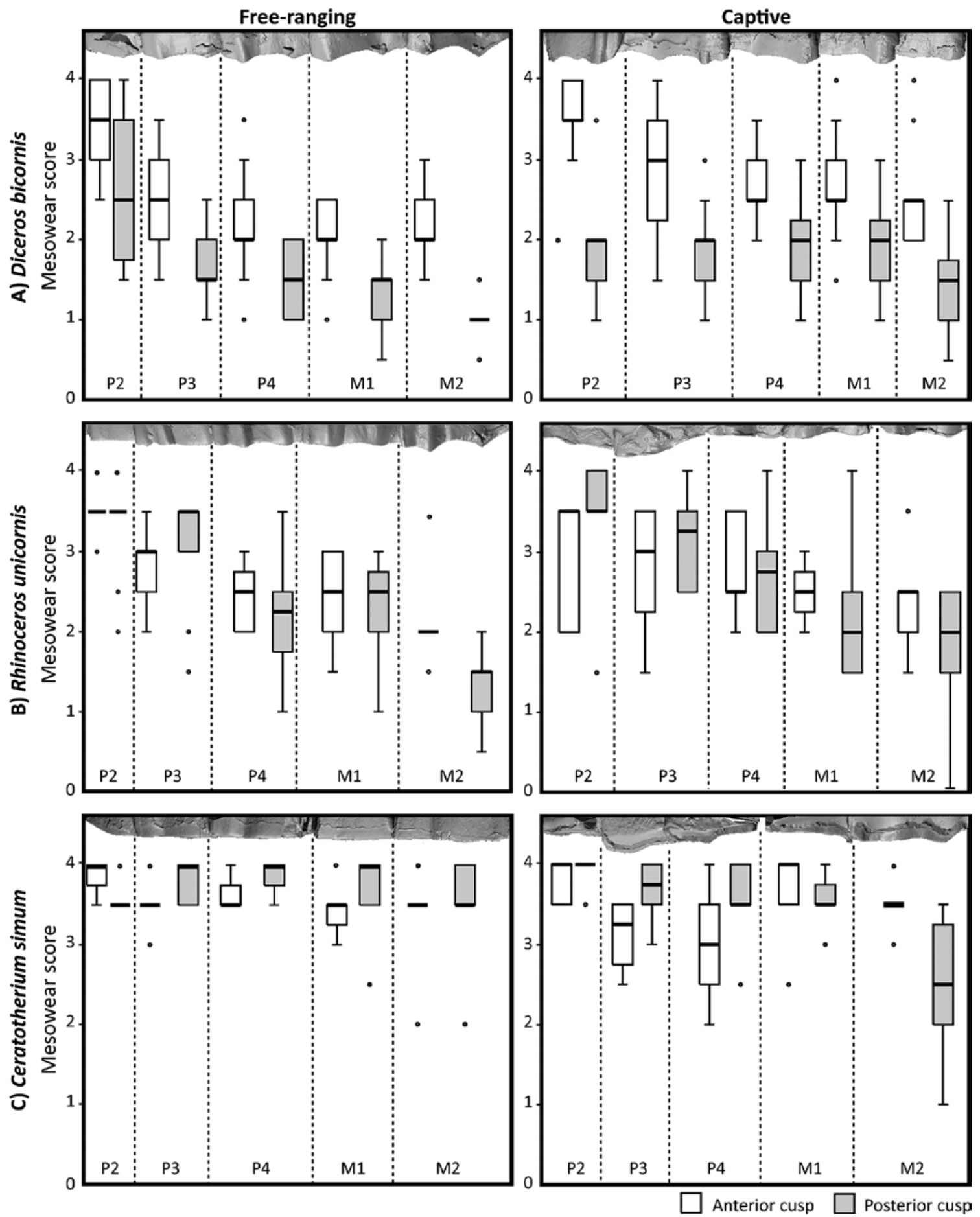

Fig. 1. Comparison of the mesowear scores for each tooth and cusp position of free-ranging and captive (a) Diceros bicornis, (b) Rhinoceros unicornis and (c) Ceratotherium simum. Boxplots denote the median (middle line), the upper and lower quartile (box limits), the outside interquartile range (IQR, whiskers), and outliers (defined as 1.5 times above or below the IQR). 3D scans of typical maxillary tooth rows from free-ranging and captive D. bicornis, $R$. unicornis and $C$. simum based on the similarity of their mesowear scores to the sample mean (Specimen identification: L-R: NMB-1021034, NMP-25963, AMNH-54455, ZMH-83585, NHM-752384, NHM-2_03). Note less even tooth wear in the captive specimens. 


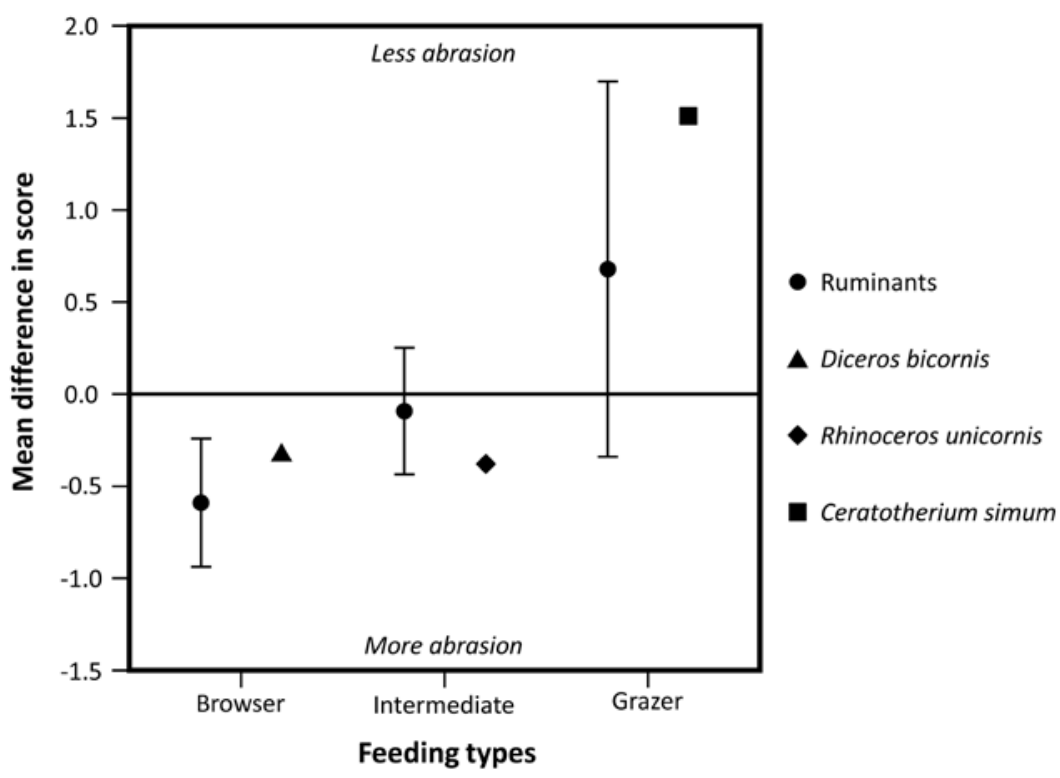

Fig. 2. Comparison of the mean score difference between captive and freeranging ruminants and rhinoceroses (free-ranging - captive). The ruminant data is from Kaiser et al. (2009) and is a score difference for the whole M2 tooth position in the method of Fortelius and Solounias (2000). Rhino data, including the browser Diceros bicornis, mixed feeding Rhinoceros unicornis and grazing Ceratotherium simum rhinoceros, is from this study and is a score difference for the posterior cusp of M2 in the method of Fortelius and Solounias (2000) with rhinoceros adjusted OR. Error bars indicate standard deviation between ruminant species.

Table 1. Linear mixed-effects models comparing the cusp shape (CS) score, occlusal relief (OR) score and mesowear score for cusp and tooth positions, within free-ranging and captive animals, and between these groups, in Diceros bicornis, Rhinoceros unicornis and Ceratotherium simum. Significant differences are highlighted in bold.

\begin{tabular}{|c|c|c|c|c|c|c|c|}
\hline \multirow[t]{2}{*}{ Species } & \multirow[t]{2}{*}{ Score } & \multicolumn{2}{|c|}{ Free-ranging } & \multicolumn{2}{|c|}{ Captive } & \multicolumn{2}{|c|}{ Origin*Tooth (Cusp) } \\
\hline & & Cusp & Tooth (Cusp) & Cusp & Tooth (Cusp) & P2-P4 & M1-M2 \\
\hline \multirow{3}{*}{$\begin{array}{l}\text { Black rhino } \\
\text { (D. bicornis) }\end{array}$} & $\mathrm{CS}$ & $<0.001$ & $<0.001$ & $<0.001$ & $<0.001$ & $<0.001$ & $<0.001$ \\
\hline & OR & $<0.001$ & $<0.001$ & $<0.001$ & $<0.001$ & $<0.001$ & $<0.001$ \\
\hline & Mesowear score & $<0.001$ & $<0.001$ & $<0.001$ & $<0.001$ & $<0.001$ & $<0.001$ \\
\hline \multirow{3}{*}{$\begin{array}{l}\text { Greater one-horned rhino } \\
\text { (R. unicornis) }\end{array}$} & $\mathrm{CS}$ & 0.729 & $<0.001$ & 0.549 & 0.007 & 0.016 & 0.134 \\
\hline & OR & $<0.001$ & $<0.001$ & 0.356 & $<0.001$ & 0.003 & $<0.001$ \\
\hline & Mesowear score & 0.085 & $<0.001$ & 0.918 & $<0.001$ & 0.005 & $<0.001$ \\
\hline \multirow{3}{*}{$\begin{array}{l}\text { White rhino } \\
\text { (C. simum) }\end{array}$} & $\mathrm{CS}$ & 0.503 & 0.213 & 0.625 & $<0.001$ & $<0.001$ & $<0.001$ \\
\hline & OR & 0.013 & 0.014 & 0.264 & $<0.001$ & $<0.001$ & 0.021 \\
\hline & Mesowear score & 0.220 & 0.081 & 0.727 & $<0.001$ & $<0.001$ & $<0.001$ \\
\hline
\end{tabular}

uneven and atypical tooth wear (Fig. 1).

In captive D. bicornis, mesowear scores were significantly more abrasion-dominated in both anterior and posterior cusps of $\mathrm{P} 4, \mathrm{M} 1$ and $\mathrm{M} 2$ compared to freeranging specimens (all $p<0.05$ ) (Table 2 ). By contrast, captive specimens had significantly less abrasiondominated mesowear scores in the posterior cusp of $\mathrm{P} 2$ $\left(t_{21.30}=2.47, p=0.022\right)$. Differences were caused by a combination of both CS and OR, with significant differences in both parameters. In captive D. bicornis, $57 \%$ of $\mathrm{P} 2 \mathrm{~s}$ were excluded due to advanced wear, whereas only $27 \%$ had been excluded in free-ranging specimens.
Wear stage exclusions did not affect the mean mesowear score of the $\mathrm{P} 2$.

In $R$. unicornis, despite overall significant differences between premolars and molars, no significant differences were found between captive and freeranging specimens at individual cusp level. Captive specimens generally had blunter CS than free-ranging specimens, but, in both groups, score variance was high. In the posterior cusp of M2, mean OR and mesowear score differences between free-ranging and captive animals were similar to $D$. bicornis.

In captive $C$. simum, CS, OR and mesowear scores 


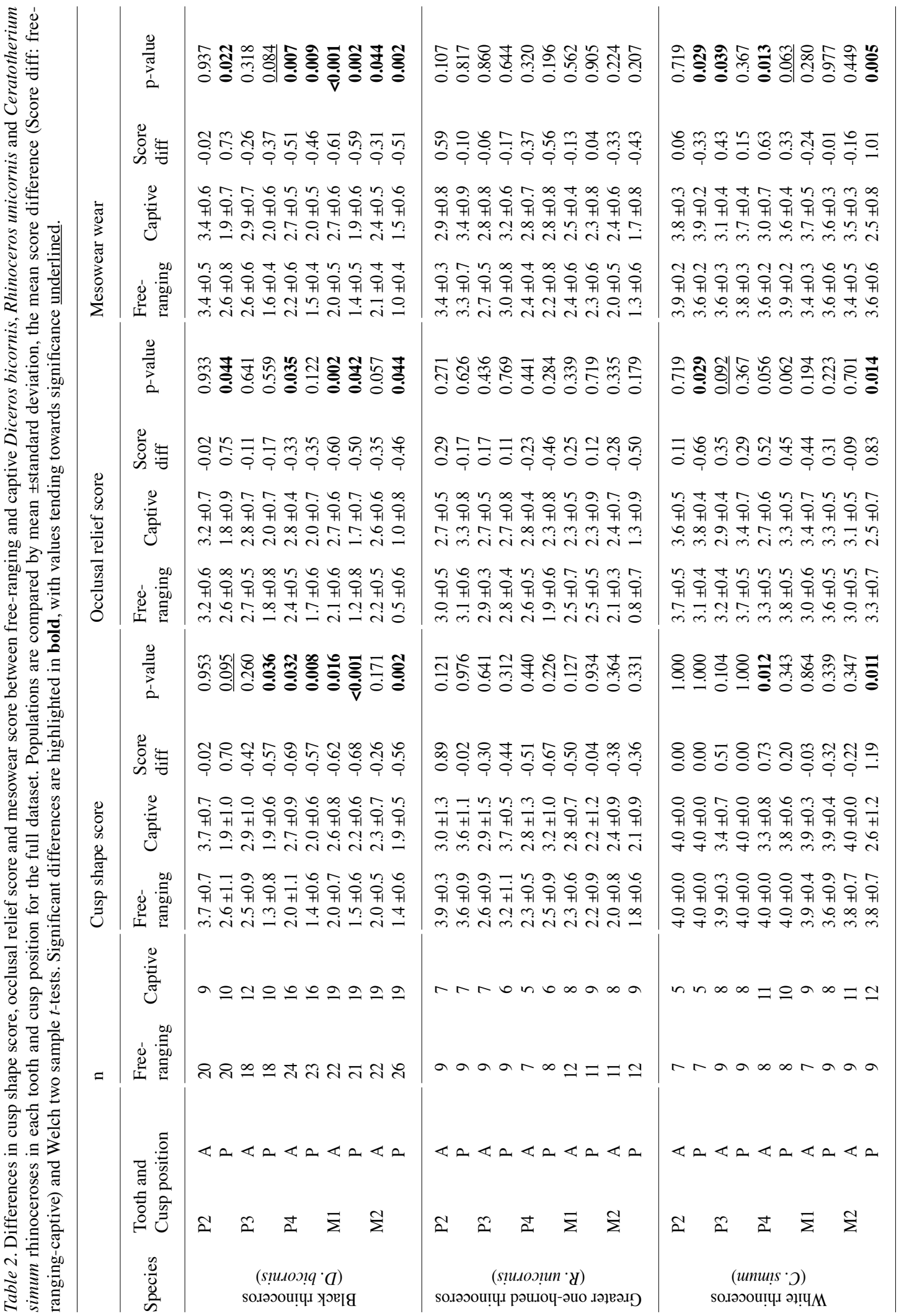


varied, revealing both significantly more and less abrasion-dominated wear patterns than their freeranging conspecifics. The posterior cusp of M2 was significantly sharper $\left(t_{17.53}=2.83, p=0.011\right)$ and higher $\left(t_{16.91}=2.7262, p=0.014\right)$ in captive than in free-ranging specimens.

In 'classical' mesowear, D. bicornis had a mean score difference in the posterior cusps of $\mathrm{M} 2$ of -0.33 (freeranging mean $=0.6 \pm 0.5$; captive $=0.9 \pm 0.5$ ), $R$. unicornis $-0.39(0.8 \pm 0.4 ; 1.2 \pm 0.7)$ and $C$. simum $1.5(3.7 \pm 1.0$; $2.2 \pm 1.5$ ) (Fig. 2). Despite a larger difference in $R$. unicornis than D. bicornis, no significant difference was detected in R. unicornis $\left(t_{12.04}=-1.56, p=0.144\right)$, whereas significant differences were detected between freeranging and captive $D$. bicornis $\left(t_{37.66}=-2.15, p=0.038\right)$ and $C$. $\operatorname{simum}\left(t_{18.89}=2.78, p=0.012\right)$.

\section{Cusp and tooth-specific wear signatures}

In both free-ranging and captive $D$. bicornis, anterior cusps were significantly more abrasion-dominated than posterior cusps (LME: all $p<0.001$ ) (Table 1). By contrast, no significant differences were observed in CS and mesowear scores between cusps in free-ranging and captive R. unicornis and C. simum. Some OR cusp differences were detected in free-ranging $R$. unicornis and $C$. simum, whereas no differences were detected in captive animals.

Tooth position differences were detected in both free-ranging and captive $D$. bicornis (all $p<0.001$ ) and $R$. unicornis (all $p<0.01$ ). In contrast to free-ranging black rhinoceroses that exhibited a negative tooth wear gradient with teeth becoming less abrasion-dominated from P2-M2, captive black rhinoceroses only exhibited a significantly blunter CS in the anterior cusp of P2 $\left(F_{4,37}=4.91, p=0.002\right.$; Dunnett's T3 post-hoc M1-M2: $p<0.01)$ and a significantly higher $\mathrm{OR}$ in the posterior cusps of M2 ( $F_{4,37}=4.97, p=0.001$; P3-P4: $\left.p<0.05\right)$ (Fig. 1). In $C$. simum, captive specimens exhibited larger differences in CS, OR and mesowear score $(p<0.001)$ along the tooth row than free-ranging conspecifics (OR: $p=0.014)$. Differences in captivity were predominantly due to a significantly sharper M2 (P2-M1: $p<0.05)$ and higher posterior cusp of M2 (P2-M1: $p=0.009)$.

\section{Discussion}

The results indicate that captive Diceros bicornis (browsers) exhibit more abrasion-dominated tooth wear than their free-ranging conspecifics, whereas captive
Ceratotherium simum (grazers) exhibit less abrasiondominated tooth wear, particularly in the posterior cusp of M2. In Rhinoceros unicornis (mixed-feeder), fewer differences were exhibited between the free-ranging and captive animals. Overall, differences in tooth wear pattern between the species were less pronounced in captive than in free-ranging rhinoceroses, particularly in cusp shape (CS), which did not significantly differ in the posterior cusp of M2. CS convergence indicates that the abrasiveness and/or physical properties of the diets fed in captivity are similar across all rhinoceros species. Whilst this may not be problematic for high-crowned C. simum, high-abrasion diets for low-crowned D. bicornis and also $R$. unicornis could result in the premature loss of tooth functionality, leading to reduced food processing ability and, consequently, malnourishment.

\section{Limitations}

Although a method for taking dental impressions from live rhinoceroses exists (Wucher, 1994), measurements of living specimens were not possible due to the necessity of immobilising animals for the procedure. Instead, dental casts of museum specimens were used, for which no feeding records were available. Therefore, it cannot be stated with certainty whether our findings are representative of current captive feeding practices. Individual age was indirectly controlled for in this study using functional wear stages; nevertheless, mesowear is affected by ontogeny (Rivals et al., 2007) and age effects cannot be excluded completely. The sample sizes of $R$. unicornis $(\mathrm{n}=11)$ and $C$. simum $(\mathrm{n}=15)$ were more limited than that of D. bicornis $(\mathrm{n}=23)$. Mesowear scoring for rhinoceroses uses different OR boundaries than ruminants; thus direct comparisons with other taxa should be limited to qualitative evaluations.

\section{Differences between the wild and captivity}

Overall, captive D. bicornis had more abrasion-dominated CS, OR and, consequently, more abrasiondominated mesowear scores than their free-ranging conspecifics. Clauss et al. (2007) and Kaiser et al. (2009) suggested increased abrasion may be due to a higher intake of abrasives as plant phytoliths (silica) via grass products (such as grass hay, but also others like grain bran), and also via silica-based flow enhancers in pelleted diets. Clauss and Hatt (2006) reported two cases of excessively worn teeth in D. bicornis fed on grass hay. The causes of tooth wear are currently debated in the scientific literature, with some arguing 
that environmental abrasives have more influence (Damuth and Janis, 2011; Lucas et al., 2013). The high impact of external abrasives on tooth wear (Healy and Ludwig, 1965) notwithstanding, Schulz et al. (2013) recently found that the 3D surface textures of rabbits fed grass or lucerne distinctly differed, indicating that internal abrasives also affect dental tissue. Additionally, Rabenold and Pearson (2011) demonstrated that molar enamel thickness related to the phytolith content of the diet in 12 primate species, which suggests that increased dental durability also evolved as an adaptation to the effect of internal abrasives. Kaiser et al. (2009) suggested that an increase in environmental abrasives is unlikely in captivity because of increased feeding hygiene and industrial processing techniques for feeds designed to minimise soil contamination. Castell (2005) reported higher faecal acid insoluble ash (silica) values for captive D. bicornis $(3.7 \pm 1.9 \%$ dry matter [DM], range 1.2-10.5) than reported for free-ranging $D . b i$ cornis $(1.7 \pm 0.6 \% \mathrm{DM}$; Hummel et al., 2011), but approaching the range measured in free-ranging C. simum $(7.5 \pm 1.3 \% \mathrm{DM})$, indicating that the intake of abrasives (whether dietary, environmental, or both) is higher in captive than free-ranging browsers. Therefore, dietspecific properties may also play a significant role in tooth wear, and abrasive feeds may be causing excessive tooth wear in captive browsers.

The intrinsic toughness, physical form and chemical properties of the diet may also affect tooth wear. In domestic horses, feeding pelleted compound diets increases the vertical and decreases the lateral excursion of the chewing movement (Bonin et al., 2007). Taylor et al. (2013) suggested an increased vertical upstroke could blunt sharp cusp tips. In captive D. bicornis, CS was significantly blunter than in free-ranging specimens, which could also be caused by chewing compound feeds. Furthermore, chewing higher proportions of compound feeds, in parallel to similar feeding practices, could explain the lack of difference in CS scores between rhinoceros species in captivity. Imbalances of calcium $(\mathrm{Ca})$, phosphorus $(\mathrm{P})$ and/or vitamin D3 have also been shown to affect tooth growth and wear rates (McRoberts et al., 1965; Harcourt-Brown, 1996). Low serum Ca and imbalanced Ca:P ratios have been reported in captive ruminants, with enamel hypoplasia and urolithiasis in captive giraffes (Miller et al., 2003; Franz-Odendaal, 2004). By contrast, hypophosphatemia has been reported in captive $D$. bicornis (Dennis et al., 2007). The link between mineral imbalances and tooth wear should be explored further, but might not be a substantial contributing factor in captive rhinoceroses.

In $R$. unicornis, overall differences were detected between free-ranging and captive animals, but differences were not significant at individual cusp level. Taylor et al. (2013) suggested variability in scores in free-ranging $R$. unicornis may be due to seasonal variation in diet (53-87\% grass; Pradhan et al., 2008). Variation in captivity likely reflects differences in feeding practices between institutions. The CS, OR and mesowear scores of free-ranging $R$. unicornis are closer to scores attained by free-ranging $D$. bicornis rather than free-ranging $C$. simum, which indicates a relatively low ingestion of environmental abrasives (Taylor et al., 2013). Compared to ruminant intermediate feeders studied by Kaiser et al. (2009), R. unicornis appeared to experience slightly more abrasion in captivity (Fig. 2). In addition to these scores, the generally low crown height of $R$. unicornis (Janis, 1988) indicates that high-abrasion diets may not be suitable for captive individuals of this species.

In captive $C$. simum, scores varied considerably along the tooth row, which indicates teeth are not wearing evenly. The posterior cusp of M2, the cusp typically used to interpret diet, is significantly higher and sharper than that of their free-ranging conspecifics, indicating the ingesta of captive $C$. simum is less abrasive. Kaiser et al. (2009) suggest captive grazers may experience less abrasion-dominated tooth wear due to reduced dietary and environmental abrasives because of the temperate climate, industrial feed processing techniques and increased feeding hygiene. In addition, the lateral excursion while chewing pelleted compound feed may be insufficient to wear the entire occlusal surface, which may facilitate the development of sharp enamel points on the edges of teeth and cause uneven tooth wear (Bonin et al., 2007). Elia et al. (2010) also found that domestic horses chewed more when fed hay $(43,476$ chews/day) than on pelleted diets (10,036 chews/day), which could decrease levels of tooth wear.

\section{Cusp and tooth position differences}

In both free-ranging and captive D. bicornis, anterior cusps were significantly more abrasion-dominated than posterior cusps. Rhino teeth are asymmetrical, with anterior cusps proportionally smaller than the posterior. Taylor et al. (2013) speculated that cusp differences in rhinoceroses are morphological adaptations to browse. Despite more abrasion-dominated scores, captive $D$. bicornis still exhibited significant differences between cusps, suggesting a morphological influence. This 
means that mesowear does not only reflect diet but also structural elements, which raises questions about the effects of tooth morphology and occlusion on the development of mesowear patterns and their functional relevance. However, anterior and posterior cusp rows were both significantly different between free-ranging and captive animals, which suggests that both cusps were also affected by ingesta-specific properties.

Free-ranging $D$. bicornis and $R$. unicornis exhibited a negative tooth wear gradient and free-ranging $C$. simum exhibited homogenous tooth wear (Taylor et al., 2013). By contrast, fewer differences were exhibited in tooth wear gradients between captive species. Several intrinsic (jaw biomechanics) and extrinsic factors (ingesta abrasives) might explain tooth wear gradients. Taylor et al. (2013) suggested tooth wear gradients may be caused by ingesta abrasiveness, because free-ranging C. simum consume high absolute amounts of ingesta abrasives, which will override other signals. The results of this study corroborate an ingesta-specific influence because the gradients differed between free-ranging and captive animals. Environmental abrasives probably affect the anterior teeth more severely before being mixed into the bolus. Captive D. bicornis may consume less environmental abrasives and more endogenous dietary abrasives. Thus, captive $D$. bicornis may experience less relative changes in abrasiveness along the tooth row and an overall increase in the absolute ingesta abrasiveness, leading to more homogenous tooth wear. Captive $C$. simum may experience a reduction in the absolute abrasiveness of ingesta compared to freeranging conspecifics, which may lead to more pronounced relative changes in wear from $\mathrm{P} 2-\mathrm{M} 2$. The results do not negate a role of jaw biomechanics, as the OR of the posterior cusp of M2 of all captive specimens was higher than more anterior tooth positions.

In free-ranging $D$. bicornis, the $\mathrm{P} 2$ was significantly more abrasion-dominated than the other tooth positions, which Taylor et al. (2013) suggest may indicate the P2 has a role in food cropping as rhinoceroses do not have occluding incisors. By contrast, captive D. bicornis had homogenous tooth wear between P2-M1 in the posterior cusp tooth row. In captivity, animals are mostly fed loose hay and pelleted feeds, which may not require cropping, and may be less contaminated with environmental abrasives, such as dust adherent on browse. Therefore, food presentation, particularly the combination of reduced bite force and reduced environmental abrasives, could also affect tooth wear gradients. However, in captive D. bicornis, $57 \%$ of P2 teeth were excluded due to advanced wear compared to $27 \%$ in the free-ranging animals. Although age differences cannot be excluded, the $\mathrm{P} 2$ wear in captive specimens highlights that despite less abrasion-dominated mesowear scores, total tooth wear (volume loss) was still high (or higher) than in free-ranging specimens, which raises questions about tooth wear rate relative to mesowear pattern.

\section{Implications}

The results in rhinoceroses and ruminants (Kaiser et al., 2009) suggest that diets fed to captive browsers are more abrasive than their diet in the wild. Although fewer differences were exhibited in mixed-feeding $R$. unicornis, the low crown height of this species still suggests high-abrasion diets may not be suitable. Excessive tooth wear could have serious implications on captive animal health, welfare and longevity and, consequently, conservation and re-introduction strategies. In the past, captive-raised $D$. bicornis have been reintroduced into protected reservations. Releasing rhinoceroses with excessive tooth wear relative to age could to some extend jeopardise the viability of such programmes. By contrast, captive $C$. simum exhibited significantly less abrasion-dominated tooth wear than free-ranging conspecifics. Decreased tooth wear may result in prolonged tooth functionality, which may have a positive influence on longevity. However, insufficient tooth wear may lead to uneven wear and tooth pathologies, which could negatively impact on captive animal health and may contribute to other dental diseases. Dental health checks should therefore be part of routine animal health checks for rhinoceroses during any veterinary treatment. As mentioned above, Wucher (1994) describes a method of taking dental impressions from rhinoceroses, which could be used to aid in the diagnosis of tooth wear problems. To help prevent tooth wear problems, browsers and intermediate feeders should be fed on a dicot-based (browse) diet that is low in abrasives, including dicot-based pellets, and grazers should be fed on a monocot-based diet, especially grass and grass hay. Pelleted feed quantities should probably be reduced. Further research is required into the abrasiveness of the diets of captive wild animals.

\section{Acknowledgements}

We acknowledge the support provided by the American Museum of Natural History New York, Institute for Zoo and Wildlife Research Berlin, Museum National d'Histoire Naturelle Paris, National Museum Prague, National Museums Scotland Edinburgh, Naturhistorisches Museum Bern, Natural History Museum 
London, Staatliches Museum für Naturkunde Stuttgart, Naturhistorisches Museum Basel, Naturhistorisches Museum Wien, Naturhistoriska Riksmuseet Stockholm, Oxford University Museum of Natural History, Phyletisches Museum Jena, Forschungsinstitut und Naturmuseum Senckenberg Frankfurt/Main, Museum für Naturkunde Berlin, Zoo Basel, Zoologisches Forschungsmuseum Alexander Koenig Bonn, Zoologisches Museum Hamburg, Zoologisches Museum Zürich and Zoologische Staatssammlung München. We thank Nelson Mascarenhas (University of Hamburg) and Olaf Dülfer (University of Bonn) for technical support, Dr Jon Bridle (University of Bristol) for his support, and Dr Amy Plowman (Whitley Wildlife Conservation Trust) and Professor Innes Cuthill (University of Bristol) for helpful comments. LT was supported by the Sir Kenneth Blaxter scholarship from the British Society of Animal Science. DM was supported by the 'Forschungskredit der Universität Zürich', loan number 55220702. This research was supported by the 'Deutsche Forschungsgemeinschaft' (DFG, German Research Foundation, KA 1525 / 8-2) and is publication no. 58 of the DFG Research Unit 771 'Function and performance enhancement in the mammalian dentition - phylogenetic and ontogenetic impact on the masticatory apparatus'. We also thank Daniela C. Kalthoff and one anonymous reviewer for their helpful comments.

\section{References}

Bonin SJ, Clayton HM, Lanovaz JL, Johnston T. 2007. Comparison of mandibular motion in horses chewing hay and pellets. Equine Veterinary Journal 39: 258-262.

Castell JC. 2005. Untersuchungen zu Fütterung und Verdauungsphysiologie am Spitzmaulnashorn (Diceros bicornis). Dissertation thesis, University of Munich.

Clauss M, Hatt J-M. 2006. The feeding of rhinoceros in captivity. International Zoo Yearbook 40: 197-209.

Clauss M, Franz-Odendaal TA, Brasch J, Castell JC, Kaiser TM. 2007. Tooth wear in captive giraffes (Giraffa camelopardalis): mesowear analysis classifies free-ranging specimens as browsers but captive ones as grazers. Journal of Zoo and Wildlife Medicine 38: 433-445.

Damuth J, Janis CM. 2011. On the relationship between hypsodonty and feeding ecology in ungulate mammals, and its utility in palaeoecology. Biological Reviews 86: 733-758.

Dennis PM, Funk JA, Rajala-Schultz PJ, Blumer ES, Miller RE, Wittum TW, Saville WJA. 2007. A review of some of the health issues of captive black rhinoceroses (Diceros bicornis). Journal of Zoo and Wildlife Medicine 38: 509-517.

Elia JB, Erb HN, Houpt KA. 2010. Motivation for hay: effects of a pelleted diet on behavior and physiology of horses. Physiology \& Behavior 101: 623-627.

Fortelius M, Solounias N. 2000. Functional characterisation of ungulate molars using the abrasion-attrition wear gradient: a new method for reconstructing paleodonts. American $\mathrm{Mu}$ seum Novitates 3301: 1-36.

Franz-Odendaal TA. 2004. Enamel hypoplasia provides insights into early systemic stress in wild and captive giraffes ( $\mathrm{Gi}$ raffa camelopardalis). Journal of Zoology 263: 197-206.

Groves CP, Fernando P, Robovský J. 2010. The sixth rhino: a taxonomic re-assessment of the critically endangered Northern white Rhinoceros. PLoS One 5: e9703.

Harcourt-Brown F. 1996. Calcium deficiency, diet and dental disease in pet rabbits. Veterinary Record 139: 567-571.

Healy WB, Ludwig TG. 1965. Wear of sheeps teeth. I. The role of ingested soil. New Zealand Journal of Agricultural Research 8: 737-752.

Hummel J, Findeisen E, Südekum K-H, Ruf I, Kaiser TM, Bucher M, Clauss M, Codron D. 2011. Another one bites the dust: faecal silica levels in large herbivores correlate with high-crowned teeth. Proceedings of the Royal Society B 278: 1742-1747.

Janis C. 1988. An estimation of tooth volume and hypsodonty indices in ungulate mammals and the correlation of these factors with dietary preferences. Pp. 367-387 in: Russell DE, Santoro J-P, Signogneau-Russell D, eds, Proceedings of the Teeth revisited Proceedings of the VIIth International Symposium on Dental Morphology Mémoires du Muséum national d'Histoire Naturelle, Paris (serie C).

Kaiser TM, Brasch J, Castell JC, Schulz E, Clauss M. 2009. Tooth wear in captive wild ruminant species differs from that of free-ranging conspecifics. Mammalian Biology 74: 425-437.

Kojola I, Helle T, Huhta E, Niva A. 1998. Foraging conditions, tooth wear and herbivore body reserves: a study of female reindeer. Oecologia 117: 26-30.

Lemaître J-F, Gaillard J-M, Lackey LB, Clauss M, Müller DWH. 2013. Comparing free-ranging and captive populations reveals intra-specific variation in aging rates in large herbivores. Experimental Gerontology 48: 162-167.

Lucas PW, Omar R, Al-Fadhalah K, Almusallam AS, Henry AG, Michael S, Thai LA, Watzke J, Strait DS, Atkins AG. 2013. Mechanisms and causes of wear in tooth enamel: implications for hominin diets. Journal of The Royal Society Interface 10: 20120923.

Martin Jurado O, Clauss M, Hatt J-M. 2008. Irregular tooth wear and longevity in captive wild ruminants: a pilot survey of necropsy reports. Journal of Zoo and Wildlife Medicine 39: 69-75.

McRoberts MR, Hill R, Dalgarno AC. 1965. The effects of diets deficient in phosphorus, phosphorus and vitamin $\mathrm{D}$, or calcium, on the skeleton and teeth of the growing sheep. Journal of Agriculture 65: 1-13.

Miller M, Weber M, Valdes E, Fontenot D, Neiffer D, Robbins PK, Terrell S, Stetter M. 2003. Hypomagnesemia, hypocalcemia, and ruminitis in unglulates: an under-recognised syndrome. Proceedings of the American Association of Zoo Veterinarians, Minneapolis, USA, pp 15-20.

Müller DWH, Bingaman Lackey L, Streich WJ, Fickel J, Hatt J-M, Clauss M.2011. Mating system, feeding type and ex situ conservation effort determine life expectancy in captive ruminants. Proceedings of the Royal Society B 278: 2076-2080.

Ozaki M, Kaji K, Matsuda N, Ochiai K, Asada M, Ohba T, Hosoi E, Tado H, Koizumi T, Suwa G, Takatsuki S. 2010. The relationship between food habits, molar wear and life expectancy in wild sika deer populations. Journal of Zoology 280: 202-212.

Pradhan NMB, Wegge P, Moe SR, Shrestha AK. 2008. Feeding ecology of two endangered sympatric megaherbivores: Asian elephant Elephas maximus and greater one-horned rhinoceros Rhinoceros unicornis in lowland Nepal. Wildlife Biology 41: 147-154.

R Core Team. 2012. R: A language and environment for statistical computing. R Foundation for Statistical Computing. Vienna, Austria.

Rabenold D, Pearson OM. 2011. Abrasive, silica phytoliths and 
the evolution of thick molar enamel in primates, with implications for the diet of Paranthropus boisei. PLoS One 6: e28379.

Rivals F, Mihlbachler MC, Solounias N. 2007. Effect of ontogenetic-age distribution in fossil and modern samples on the interpretation of ungulate paleodiets using the mesowear method. Journal of Vertebrate Paleontology 27: 763-767.

Ruxton GD. 2006. The unequal variance t-test is an underused alternative to Student's t-test and the Mann-Whitney U test. Behavioral Ecology 17: 688-690.

Schulz E, Piotrowski V, Clauss M, Mau M, Merceron G, Kaiser TM. 2013. Dietary abrasiveness is associated with variability of microwear and dental surface texture in rabbits. PLoS ONE 8: e56167.

Skogland T. 1988. Tooth wear by food limitation and its life history consequences in wild reindeer. Oikos 51: 238-242.

Taylor LA, Kaiser TM, Schwitzer C, Müller DHW, Cordon D,
Clauss M, Schulz E. 2013. Detecting inter-cusp and inter-tooth wear patterns in Rhinocerotids. PLoS One 8: e80921.

Winkler DE, Kaiser TM. 2011. A case study of seasonal, sexual and ontogenetic divergence in the feeding behaviour of the moose (Alces alces Linné, 1758). Verhandlungen des naturwissenschaftlichen Vereins Hamburg 46: 331-348.

Wucher M. 1994. A technique for making dental impressions and casts of immbolised black rhinoceros (Diceros bicornis) and white rhinoceros (Ceratotherium simum). Proceedings of a Symposium on "Rhinos as Game Ranch Animals", Onderstepoort, pp. 164-167.

Received: 2 November 2013

Revised and accepted: 21 January 2014

Published online: xx March 2014

Editor: V. Nijman

\section{On-line Supplementary Information (SI)}

S1. Museum and specimen information. 
S1. Museum and specimen information.

\begin{tabular}{|c|c|c|c|}
\hline \multirow{2}{*}{$\begin{array}{c}\text { Museum } \\
\text { Abbreviation }\end{array}$} & \multirow{2}{*}{ Museum Name } & \multicolumn{2}{|c|}{ Specimen identification } \\
\hline & & Free-ranging & Captive \\
\hline AMNH & $\begin{array}{l}\text { American Museum of Natural } \\
\text { History New York }\end{array}$ & $54454,54455,51854,146718$ & \\
\hline IZW & $\begin{array}{l}\text { Institute for Zoo and Wildlife } \\
\text { Research Berlin }\end{array}$ & & $\begin{array}{l}371 / 2003,0175,538,2001, \\
835 / 93\end{array}$ \\
\hline MHN & $\begin{array}{l}\text { Museum National d'Histoire } \\
\text { Naturelle Paris }\end{array}$ & A2277 & $\begin{array}{l}\text { 1944-278, 1961-195, 1974- } \\
\text { 124, 1960-59, 1967-101, } \\
2005-297\end{array}$ \\
\hline NHB & $\begin{array}{l}\text { Naturhistorisches Museum } \\
\text { Bern }\end{array}$ & 1021034 & 10594, n.N.082 \\
\hline NHM & $\begin{array}{l}\text { Natural History Museum } \\
\text { London }\end{array}$ & $\begin{array}{l}\text { 1874.11.2.2, 1876.2.15.5, } \\
\text { 19.7.15.511, 1907.2.26.1, } \\
\text { 1948.1.28.6, 1962.7.6.1, } \\
\text { 1962.7.6.5, 1962.7.6.6, } \\
\text { 1967.7.6.4, 1976.9.26.6, } \\
2.11 .18 .7,1951.11 .30 .2, \\
72.12 .30 .1,72.739,84.1 .22 .1+2, \\
1967.8 .31 .4,25.5 .23 .1, \\
52.12 .9 .1,75.2384\end{array}$ & 1961.5.10.1 \\
\hline NHS & $\begin{array}{l}\text { Staatliches Museum für } \\
\text { Naturkunde Stuttgart }\end{array}$ & $32018,7564,1218$ & \\
\hline NMAB & Naturmuseum Augsburg & & 01,02 \\
\hline NMB & $\begin{array}{l}\text { Naturhistorisches Museum } \\
\text { Basel }\end{array}$ & 7351, C.1798 & n.N.007 \\
\hline NMP & National Museum Prague & & $\begin{array}{l}165,2007,25963,25964, \\
47655,48347,489,1 / 188, \\
2006,47145\end{array}$ \\
\hline NMS & $\begin{array}{l}\text { National Museums Scotland } \\
\text { Edinburgh }\end{array}$ & & $\begin{array}{l}\text { 200.369, } 2008 \text { unreg, } \\
\text { 2003.5, 2008.124, 2000.33, } \\
\text { 2004.75, 2005.129.2, } \\
2008.127,2009.10\end{array}$ \\
\hline NMW & $\begin{array}{l}\text { Naturhistorisches Museum } \\
\text { Wien }\end{array}$ & 4279,4291 & 55210 \\
\hline NRM & $\begin{array}{l}\text { Naturhistoriska Riksmuseet } \\
\text { Stockholm }\end{array}$ & A591324, A591596 & \\
\hline OUM & $\begin{array}{l}\text { Oxford University Museum of } \\
\text { Natural History }\end{array}$ & 7118,3827 & \\
\hline PMJ & Phyletisches Museum Jena & 651 & \\
\hline SMF & $\begin{array}{l}\text { Forschungsinstitut und } \\
\text { Naturmuseum Senckenberg } \\
\text { Frankfurt am Main }\end{array}$ & $22660,699,664$ & 15934,40543 \\
\hline Zoo Basel & Zoo Basel & & Zoo Basel \\
\hline ZFMK & $\begin{array}{l}\text { Zoologisches } \\
\text { Forschungsmuseum Alexander } \\
\text { Koenig Bonn }\end{array}$ & & 88.16 \\
\hline ZMB & Museum für Naturkunde Berlin & $\begin{array}{l}35744,40053,41480,46166, \\
83230,83232\end{array}$ & \\
\hline $\mathrm{ZMH}$ & $\begin{array}{l}\text { Zoologisches Museum } \\
\text { Hamburg }\end{array}$ & $\begin{array}{l}35744,40053,41480,46166, \\
83230,83232,2551,2552\end{array}$ & $8405,9328,8385,10060$ \\
\hline ZMZ & Zoologisches Museum Zürich & $83226,10806,10927$ & $\begin{array}{l}18129,19660,20165, \\
20273\end{array}$ \\
\hline ZSSM & $\begin{array}{l}\text { Zoologische Staatssammlung } \\
\text { München }\end{array}$ & $\begin{array}{l}\text { 1963/160, AM416, 1912/4199, } \\
\text { 1912/4202 }\end{array}$ & $2001 / 33$ \\
\hline
\end{tabular}

